CHAPTER 9

\title{
The new Garba Guracha palynological sequence: Revision and data expansion
}

\author{
Graciela Gil-Romera ${ }^{1}$, Mekbib Fekadu ${ }^{2}$ \& Lars Opgenoorth \\ Department of Ecology, Philipps-Marburg University, Marburg, Germany
}

David Grady \& Henry F. Lamb ${ }^{3}$

Department of Geography and Earth Sciences, Aberystwyth University, Aberystwyth, United Kingdom

Lucas Bittner \& Michael Zech

Heisenberg Chair of Physical Geography, Technische Universität Dresden, Dresden, Germany

Georg Miehe

Department of Geography, Philipps-Marburg University, Marburg, Germany

\subsection{SITE DETAILS}

In the context of the DFG-funded project 'Mountain Exile Hypothesis' (FOR2358) we retrieved a $15.5 \mathrm{~m}$ long sediment core from Garba Guracha (GG) (Bale Mountains National Park, Ethiopia BMNP) during February 2017. A 16,000 year record of 62 pollen samples has been previously produced from GG by Umer et al. (2007). In this data paper, we present a new palynological and macrocharcoal record, with 259 pollen and 1301 charcoal samples covering the last $14 \mathrm{ka}$ BP. Previous versions of the charcoal and Erica pollen records can be found in Gil-Romera et al. (2019). The depth-age model for the presented record in this new manuscript can be found in Bittner et al. 2020.

GG is a small $(500 \times 300 \mathrm{~m}), 6 \mathrm{~m}$ deep lake $\left(6.9^{\circ} \mathrm{N}, 39.9^{\circ} \mathrm{E}\right)$, lying in a cirque at $3950 \mathrm{~m}$ asl in the BMNP of the Bale-Arsi Massif, Ethiopia (Figure 1). GG sits in a north-facing valley of the Sanetti plateau that was locally glaciated during the Last Glacial Maximum (Ossendorf et al. 2019; Tiercelin et al. 2008). High seasonality characterizes the rainfall pattern with a dry season from November to February and a bimodal wet season from March to October. Local rainfall patterns in BMNP present an altitudinal (lowlands to highlands) and latitudinal ( $\mathrm{N}$ to S) increasing rainfall gradient, defining the vegetation zonation (Miehe and Miehe 1994). GG lies between the Ericaceous and afroalpine vegetation belts, however only dispersed Erica spp.

\footnotetext{
${ }^{1}$ Other affiliation: Department of Geoenvironmental Processes and Global Change, Pyrenean Institute of Ecology-CSIC, Zaragoza, Spain

${ }^{2}$ Other affiliation: Department of Biology, Addis Ababa University, Addis Ababa, Ethiopia

${ }^{3}$ Other affiliation: Department of Botany, Trinity College Dublin, Dublin, Ireland
} 

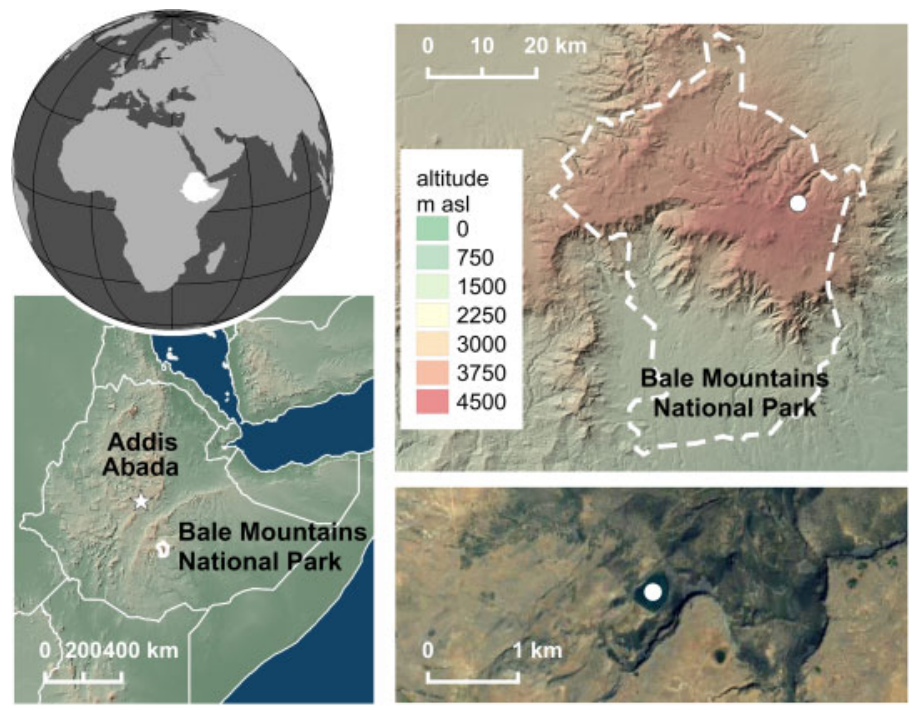

Figure 1. Map of the study area (Bale Mountains National Park) situated east of the Ethiopian Rift Valley in Ethiopia, East Africa (made by Dr. Miguel Sevilla-Callejo). Layout of satellite image is from TerraMetrics@ for Google Maps (2019).

stands are present on the south east slopes of the catchment. The dominant plant communities around the lake consist of Alchemilla haumannii and Helichrysum splendidum-H. citrispinum shrublands. The northern lowland area has been heavily transformed by human activities and the natural vegetation remaining are dry afromontane forests dominated by Podocarpus falcatus and Olea europaea to $2700 \mathrm{~m}$ asl, followed by Myrica salicifolia and Dodonaea viscosa communities that give way at the upper forest limit to Hagenia abyssinica-Juniperus procera and Schefflera spp. communities up to $3200 \mathrm{~m}$ asl. Erica trimera and E. arborea, together with Hypericum revolutum form the Ericaceous belt found from $3200 \mathrm{~m}$ to $4000 \mathrm{~m}$ asl. The southern slopes receive rainfall throughout the year presenting a mixed broadleaved Afromontane rainforest dominated by Pouteria aidssima, Ficus mucuso but without Juniperus (Friis et al. 2010).

\subsection{SEDIMENT DESCRIPTION AND METHODS}

We retrieved two overlapping cores at $4.8 \mathrm{~m}$ water depth with a Livingstone corer from a raft. We obtained sediments to a maximum sediment depth of $1550 \mathrm{~cm}$. Details of core retrieval, sedimentology and lithofacies can be found in Bittner et al. (2020). Charcoal particles and pollen data presented here cover from 13,700 to $94 \mathrm{cal}$. yr BP, as the bottom most sections were formed by highly inorganic sediments yielding counts too low to be statistically significant. Charcoal was sampled at contiguous intervals (1300 samples, Gil-Romera et al. 2019) and we analysed 259 pollen samples using a modified version of the laboratory protocol of Moore et al. (1994), adding Lycopodium spores (Lund University, batch \# 1031, 15,636 spores per tablet, SD 592) to estimate concentration and pollen accumulation rates (PAR). A zonation was applied in order to facilitate the pollen data set interpretation. These pollen assemblage zones were done using a CONISS (Grimm 1987) cluster analysis. We calculated the Principal Curve (PrC) for our pollen assemblage to summarize the palynological compositional turnover along one ordination 




Figure 2. Age-depth model for Garba Guracha (GG) presenting the prior parameters into the Bayesian framework on the upper panels Modified from Bittner et al. (2020).

axis (De'ath 1999). Charcoal and pollen plots and numerical analyses were done using several R packages (R Core Team 2012). Full code, data and further details can be downloaded from Gil-Romera's GitHub repository shorturl.at/rxMW1 and from Neotoma database.

\subsection{DATING}

The 15.9 ka BP GGU17-1B age-depth model was built combining 48 dated samples using the Bayesian framework of the Bacon package in R (Blaauw and Christen 2011; R Core Team, 2017) (Figure 2). Dates used in this model can be found in supporting online material, and chronological methods are described in Bittner et al. (2020).

\subsection{INTERPRETATION}

We identified 98 taxa and counted an average of 456 pollen grains $(\mathrm{SD}=120)$. We define six pollen zones (GGU1-GGU6) representing the last $13.7 \mathrm{ka}$ BP of vegetation dynamics in GG area (Figure 3).

\subsubsection{GGU1 Afroalpine vegetation (1170-1031 cm, 13.7-13 ka BP, 30 pollen samples)}

The landscape was dominated by afroalpine vegetation reflecting cool, dry conditions (Figure 3 ). PAR values indicate a clear expansion of afroalpine and dry forest communities, with a minor development of the Ericaceous belt. At $c .13 .1 \mathrm{ka} \mathrm{BP}$ we identify a large pulse of biomass burning that may be related to local fire activity. However, we cannot discard the possibility that charcoal particles accumulated on a frozen lake surface (Tiercelin et al. 2008) prior to the beginning of our record, which were deposited on the lake bottom after the ice melted. 


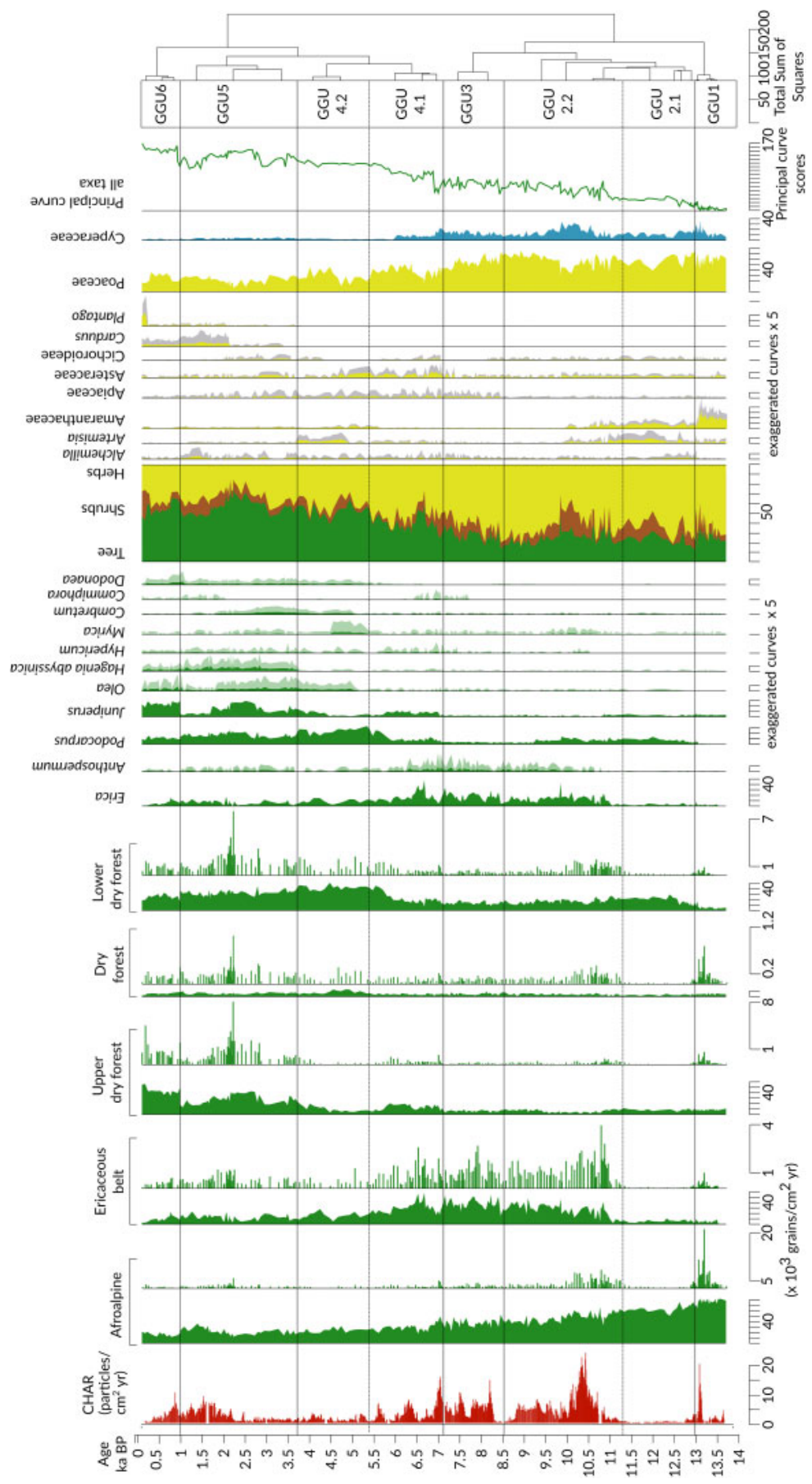

Figure 3. Pollen diagram for lake Garba Guracha at $3950 \mathrm{~m}$ asl. Analyst: Graciela Gil-Romera. Vegetation belts are presented in percentages (filled silhouette) and PAR (in bars). Taxa included in each group can be found in the dictionary stored at shorturl.at/rxMW1. 


\subsubsection{GGU2 Afroalpine-Ericaceous belt turnover $(1030-637 \mathrm{~cm}, 13-8.5 \mathrm{ka} \mathrm{BP,} 80$ pollen samples)}

\subsubsection{GGU 2.1 Amaranthacea-Poaceae dominating (1030-900 cm, 13-11.2 ka BP, 26 pollen samples)}

Afroalpine herbs (e.g. Amaranthaceae) abruptly decrease at $12.5 \mathrm{ka}$ BP coinciding with Younger Dryas-like conditions (YD). YD conditions have been described in Eastern Africa before (Talbot et al. 2007) broadly concurring in time (12.9-11.7 ka BP) with the YD in the Greenland ice cores (GS1, Rasmussen et al. 2006). While the YD may not have had a great impact on most lowland African records, afroalpine communities clearly declined, especially the PAR of these communities, except Artemisia which does not decrease in abundance. The lower forest seems to expand despite PAR suggesting a poor development. These vegetation dynamics may be pointing to a short and abrupt cold, dry pulse at these altitudes.

\subsubsection{GGU 2.2 Expansion of Erica (899-637 cm, 11.2-8.5 ka BP, 54 pollen samples)}

There is a notable expansion of most vegetation communities, as indicated by all PAR values and increased PrC scores. This expansion is especially important in the Ericaceous belt, potentially responding to increasing temperatures and moisture availability linked to the African Humid Period onset (AHP) (deMenocal et al. 2000). Under those conditions Erica thickets may have fostered biomass burning during the dry season, activating a fire feedback well known in the local modern-day fire ecology (Johansson and Granström 2014). Such a mechanism would explain the Ericaceous PAR variability - that does not always correspond to that of abundance - where expansion events are followed by burning that leads to new resprouting thickets and therefore new biomass to be burnt. In addition, dry forests keep a relatively constant and low presence despite an initial PAR increase, that together with the Erica dominance, may suggests the establishment of a wetter and warmer phase during this period. The relative expansion of hydrophytes such as Cyperaceae would also indicate higher water availability. From 10 to 8 ka BP Poaceae expansion coincides with reduced CHAR and Erica PAR indicating a progressive opening of the landscape.

\subsubsection{GGU3 Full extension of the Ericacoeus belt $(636-549 \mathrm{~cm}, 8.5-7.2 \mathrm{ka}$ BP, 30 pollen samples)}

Erica spreads as indicated by its PAR, with a consequential biomass burning and decline in the herbal community while the dry forest boundaries keep similar PAR and abundances. We infer relatively similar climate conditions at this stage, with no clear community transformations as supported by unchanging PrC scores.

\subsubsection{GGU4 Ericaceous belt-dry montane forest turnover $(548-291 \mathrm{~cm} 7.2-3.6 \mathrm{ka}$ BP, 52 pollen samples)}

9.4.4.1 GGU4.1 Progressive Erica decline (547-418 cm, 7.2-5.4 ka BP, 33 pollen samples)

The Ericaceous belt slightly contracts at $7.2 \mathrm{ka}$ BP as the Upper dry forest boundary expands, concurring with increasing biomass burning. The Lower dry forest expands at the end of this zone, while the Ericaceous belt progressively contracts as illustrated by increased $\mathrm{PrC}$ scores. The GG landscape may have opened up further as Erica cover declines from 6 ka BP onwards, enabling a higher deposition of lowland dry forest pollen taxa, indicating progressively drying conditions.

\subsubsection{GGU4.2: Lower dry Afromontane forest expansion (417-291 cm, 5.4-3.6 ka BP, 19 pollen samples)}

The Ericaceous belt and the local biomass burning continue declining while the Lower dry forest boundary, dominated by Podocarpus and Olea, expands with varying pollen concentrations, 
concurring with the spread of Artemisia with equivalent values to those of zone GGU2a. This landscape succession suggests drying conditions concurring with the regional AHP termination (de Menocal et al. 2000).

\subsubsection{GGU5 Upper dry forest expansion, $(290-109 \mathrm{~cm}, 3.6-1 \mathrm{ka}$ BP, 50 pollen samples)}

This zone features the constant presence of the dry forest communities, with Juniperus dominating until c. $2 \mathrm{ka}$ BP. After this Juniperus declines in conjunction with new biomass burning and the scarce, consistent presence of ruderals (e.g. Plantago) or other herbs in the Afroalpine domain. We hypothesize that this landscape change is likely due to a dry forest upwards shift under similar climate conditions to GGU4b. Increasing human pressure from c. 2 ka BP may have triggered more frequent or intense fires to obtain new pastures at the Upper dry forest-Ericaceous Belt limit. The increase in PAR c. $2 \mathrm{ka}$ BP in all forest components might be linked to brief climate changes, as increasing temperature or short drought spells (Marshall et al. 2009).

\subsubsection{GGU6 Upper dry forests and ruderal plants presence $(108-60 \mathrm{~cm}, 1000-94 \mathrm{yr} \mathrm{BP}$, 17 pollen samples)}

The last millennium at GG presents a locally open landscape with abundantherbs, especially those indicating human agency (e.g. Plantago), with scarce Erica presence and an upwards shift of the Upper dry forest. While we cannot discount the possibility of persistent drying conditions and relative temperature changes, we understand landscape changes in this zone to be mainly human-driven.

\section{ACKNOWLEDGEMENTS}

This study was funded by the DFG research unit FOR 2358 'Mountain Exile Hypothesis'.

\section{REFERENCES}

Bittner, L., Bliedtner, M., Grady, D., Gil-Romera, G., Martin-Jones, C., Lemma, B., Mekonnen, B., Lamb, H.F., Yang, H., Glaser, B., Szidat, S., Salazar, G., Rose, N.L., Opgenoorth, L., Miehe, G., Zech, W., Zech, M., 2020, Revisiting afro-alpine Lake Garba Guracha in the Bale Mountains of Ethiopia: rationale, chronology, geochemistry, and paleoenvironmental implications. Journal of Paleolimnology, 64, pp. 293-314, 10.1007/s10933020-00138-w.

De'ath, G., 1999, Principal Curves: A New Technique for Indirect and Direct Gradient Analysis. Ecology 80, pp. 2237-2253, 10.1890/0012-9658(1999)080[2237:PCANTF]2.0.CO;2.

de Menocal, P.B., Ortiz, J., Guilderson, T., Adkins, J., Sarnthein, M., Baker, L., Yarusinski, M., 2000. Abrupt onset and termination of the African Humid Period: Rapid climate response to gradual insolation forcing. Quaternary Science Reviews, 19, pp. 347-361, 10.1016/S02773791(99)00081-5.

Friis, I., Demissew, S., van Breugel, P., 2010, Atlas of the Potential Vegetation of Ethiopia. (Copenhaguen: The Royal Danish Academy of Sciences and Letters).

Gil-Romera, G., Adolf, C., Benito, B.M., Bittner, L., Johansson, M.U., Grady, D.A., Lamb, H.F., Lemma, B., Fekadu, M., Glaser, B., Mekonnen, B., Sevilla-Callejo, M., Zech, M., Zech, W., Miehe, G., 2019, Long-term fire resilience of the Ericaceous Belt, Bale Mountains, Ethiopia. Biology Letters, 15, 20190367, 10.1098/rsbl.2019.0357. 
Grimm, E.C., 1987, CONISS: A FORTRAN 77 program for stratigraphically constrained cluster analysis by the method of incremental sum of squares. Computers \& Geosciences, 13, pp. 13-35, 10.1016/0098-3004(87)90022-7.

Johansson, M.U., Granström, A., 2014, Fuel, fire and cattle in African highlands: traditional management maintains a mosaic heathland landscape. Journal of Applied Ecology, 51, pp. 1396-1405, 10.1111/1365-2664.12291.

Marshall, M.H., Lamb, H.F., Davies, S.J., Leng, M.J., Kubsa, Z., Umer, M., Bryant, C., 2009. Climatic change in northern Ethiopia during the past 17,000 years: A diatom and stable isotope record from Lake Ashenge. Palaeogeography, Palaeoclimatolology, Palaeoecology, 279, pp. 114-127, 10.1016/j.palaeo.2009.05.003.

Miehe, S., Miehe, G., 1994, Ericaceous forests and heathlands in the Bale Mountains of South Ethiopia. Ecology and man's impact. (Hamburg: Warnke).

Ossendorf, G., Groos, A.R., Bromm, T., Tekelemariam, M.G., Glaser, B., Lesur, J., Schmidt, J., Akçar, N., Bekele, T., Beldados, A., Demissew, S., Kahsay, T.H., Nash, B.P., Nauss, T., Negash, A., Nemomissa, S., Veit, H., Vogelsang, R., Woldu, Z., Zech, W., Opgenoorth, L., Miehe, G., 2019, Middle Stone Age foragers resided in high elevations of the glaciated Bale Mountains, Ethiopia. Science, 365, pp. 583-587, 10.1126/science.aaw8942.

Rasmussen, S.O., Andersen, K.K., Svensson, A.M., Steffensen, J.P., Vinther, B.M., Clausen, H.B., Siggaard-Andersen, M.-L., Johnsen, S.J., Larsen, L.B., Dahl-Jensen, D., Bigler, M., Röthlisberger, R., Fischer, H., Goto-Azuma, K., Hansson, M.E., Ruth, U., 2006, A new Greenland ice core chronology for the last glacial termination. Journal of Geophysical Research, 111, D06102, 10.1029/2005JD006079.

R Core Team, 2012, R: A Language and Environment for Statistical Computing, (Vienna: R Foundation for Statistical Computing).

Talbot, M.R., Filippi, M.L., Jensen, N.B., Tiercelin, J.-J., 2007, An abrupt change in the African monsoon at the end of the Younger Dryas. Geochemistry, Geophysics, Geosystems, 8, Q03005, 10.1029/2006GC001465.

Tiercelin, J.J., Gibert, E., Umer, M., Bonnefille, R., Disnar, J.R., Lézine, A.M., HureauMazaudier, D., Travi, Y., Keravis, D., Lamb, H.F., 2008, High-resolution sedimentary record of the last deglaciation from a high-altitude lake in Ethiopia. Quaternary Science Reviews. 27, pp. 449-467, 10.1016/j.quascirev.2007.11.002.

Umer, M., Lamb, H.F., Bonnefille, R., Lézine, A.-M., Tiercelin, J.-J., Gibert, E., Cazet, J.-P., Watrin, J., 2007, Late Pleistocene and Holocene vegetation history of the Bale Mountains, Ethiopia. Quaternary Science Reviews, 26, pp. 2229-2246, 10.1016/j.quascirev.2007.05.004. 


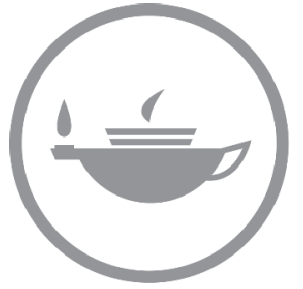

Taylor \& Francis Taylor \& Francis Group http://taylorandfrancis.com 